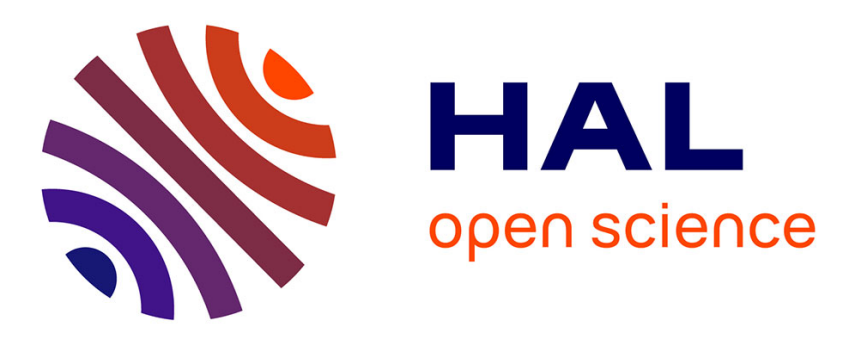

\title{
Automatic Calibration of Bed Friction Coefficients to Reduce the Influence of Seasonal Variation: Case of the Gironde Estuary
}

Nicolas Huybrechts, Hassan Smaoui, Sylvain Orseau, Pablo Tassi, Fabrice Klein

\section{To cite this version:}

Nicolas Huybrechts, Hassan Smaoui, Sylvain Orseau, Pablo Tassi, Fabrice Klein. Automatic Calibration of Bed Friction Coefficients to Reduce the Influence of Seasonal Variation: Case of the Gironde Estuary. Journal of Waterway, Port, Coastal, and Ocean Engineering, 2021, 147 (3), pp.05021004. 10.1061/(ASCE)WW.1943-5460.0000632 . hal-03196183

\section{HAL Id: hal-03196183 \\ https://hal.sorbonne-universite.fr/hal-03196183}

Submitted on 12 Apr 2021

HAL is a multi-disciplinary open access archive for the deposit and dissemination of scientific research documents, whether they are published or not. The documents may come from teaching and research institutions in France or abroad, or from public or private research centers.
L'archive ouverte pluridisciplinaire HAL, est destinée au dépôt et à la diffusion de documents scientifiques de niveau recherche, publiés ou non, émanant des établissements d'enseignement et de recherche français ou étrangers, des laboratoires publics ou privés. 
1 Automatic calibration of the bed friction coefficients to reduce the influence of their seasonal

3 Nicolas Huybrechts ${ }^{1}$, Hassan Smaoui ${ }^{2}$, Sylvain Orseau ${ }^{3}$, Pablo Tassi $^{4}$ and Fabrice Klein ${ }^{5}$

$4{ }^{1}$ Researcher, Cerema Direction Technique Eau, Mer et Fleuves and Sorbonne Universités, université de 5 technologie de Compiègne, CNRS, FRE 2012 Roberval, Centre de recherche Royallieu, CS 60 319, 60203

6 Compiègne cedex - France. nicolas.huybrechts@cerema.fr

${ }^{2}$ Researcher, Cerema Direction Technique Eau, Mer et Fleuves and Sorbonne Universités, université de technologie de Compiègne, CNRS, FRE 2012 Roberval, Centre de recherche Royallieu, CS 60 319, 60203 Compiègne cedex - France. hassan.smaoui@cerema.fr

${ }^{3}$ Post doc, Cerema Direction Technique Eau, Mer et Fleuves and Sorbonne Universités, université de technologie de Compiègne, CNRS, FRE 2012 Roberval, Centre de recherche Royallieu, CS 60 319, 60203 Compiègne cedex - France. sylvain.orseau@cerema.fr

${ }^{4}$ Researcher. Electricity of France, R\&D Department, 6 quai Watier, BP 49, 78401 Chatou Cedex, France. Laboratoire d'Hydraulique Saint Venant (ENPC-EDF/R\&D-CEREMA), 6 quai Watier, BP 49, 78401 Chatou Cedex, France.pablo.tassi@edf.fr

${ }^{5}$ Engineer. Grand Port Maritime de Bordeaux, 152 quai de Bacalan - CS 41320 - 33082 BORDEAUX CEDEX, France.f-klein@bordeaux-port.fr 
33 An automatic procedure to identify the bed friction coefficient is tested on a 2D hydrodynamic model of the Gironde estuary (France). The proposed procedure involves an optimization algorithm based on evolution strategy, namely CMA-ES (Covariance Matrix Adaptation Evolution Strategy). Without optimization, application of the same friction distribution to different hydrological conditions leads to significant relative error in water level prediction up to $20-30 \%$. For the tested configuration, 300 runs seemed to be sufficient to reach an optimal value whereas additional 200 runs would help to gain an accuracy of few millimetres (or $0.3 \%$ ). In order to reach the same level of accuracy for the different hydrological configurations, it is necessary to adapt for each configuration the bed friction coefficient. Such behaviour tends to confirm a seasonal variation of the friction coefficient and this particularly in the central part of the estuary. Different relationships of the friction coefficient according to the flowrate have been incorporated inside the 2D hydrodynamic model. These relationships effectively allow to maintain an accurate prediction of the water levels close to $10 \%$ for a wide range of hydrological configurations. 


\section{INTRODUCTION}

55 The tide propagation inside estuary is mainly affected by the modification of the flow section and by energy loses due to bed friction (Le Floch 1961). Converging sections tend to increase

57

the tidal amplitude whereas bottom friction rather decreases this amplitude (Le Floch 1961). In the estuarine uppest part, the interactions between tide and river discharge also impact the tidal propagation (Moldwin 2016). For instance, the flowrate magnitude influences the location of turbidity maximum (TM) and associated mud deposition (Sottolichio et al 2001). The presence of fresh mud deposit induces a modification of the bottom friction (van Rijn 2007) and thus the tide attenuation. In contrast, harmonic analysis is generally used by harbours to predict the water level (Moldwin 2016). Prediction based on harmonic analysis is valid for harbours located near the shore but it becomes less accurate for ports located inside the estuary where interaction between river and tide becomes significant. A typical example is the Port of Bordeaux located $100 \mathrm{~km}$ upstream the mouth of the Gironde estuary. The macrotidal Gironde Estuary is located in South-West France covering a surface of $635 \mathrm{~km}^{2}$ from the Bay of Biscay to $170 \mathrm{~km}$ landward (Fig. 1). The estuary is characterized by a complex

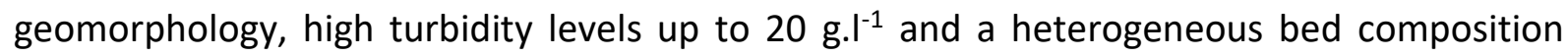
(Allen 1972, Castaing 1981). Over the years, a large number of hydrodynamic models with different complexity levels have already been developed. These models generally aimed at tracking the turbidity maximum zone (Sottolichio et al 2001, Jalon-Rojas et al., 2015) with twodimensional vertical (2DV) or three-dimensional approaches (3D) to compute the hydrodynamics, sediment transport, and salt intrusion. Alternatively, Huybrechts et al. (2012) proposed a 2D depth-averaged horizontal model $(2 \mathrm{DH})$ that showed to be a good compromise between computational cost and accurate solution to efficiently capture the main 
hydrodynamic processes. Fast and robust models are indeed required in operational tools applied to various alert control systems, including flood control application (Laborie et al 2014) and transport processes, such as sediment matter (Huybrechts and Villaret 2013, Orseau et al. 2020a), or pollutants in the environment. The model developed by Huybrechts et al. (2012) has been further applied to forecast the ship welcoming capacity inside the Gironde estuary for an interval of 36 hours (Orseau et al 2020b). Huybrechts et al. (2012) calibrated the bed friction coefficients by a trial and error procedure in order to reach water level differences lower than $15 \mathrm{~cm}$ at the estuary mouth (Verdon, Fig. 1) and at the central part of the estuary (Pauillac, Fig. 1). The calibration and the validation of this model have been performed with field measurements acquired in August 2006 and October-November 2009. These two events are characterized by low river discharges and calm weather conditions. The hydrodynamic model included river and tidal forcing whereas storm surges were not considered. The update of the Huybrechts et al.'s model (2012) to recent bathymetric information coming from up-today bathymetric surveys makes therefore necessary to assess the validity of the previous friction calibration procedure. In contrast to a flood control application where a robust calibration is needed especially for high water levels or storm conditions, a ship route plan requires a robust calibration for a wider range of hydrological condition. Therefore, the accuracy of the model needs to be evaluated under different flow scenarios and weather conditions. Since the trial and error methodology is not suitable to build a friction calibration procedure valid for different hydrological conditions, it is rather proposed to couple the hydrodynamic model with an optimization tool. As discussed by Dung et al. (2011), automatic calibration is becoming popular for water-related applications mainly for groundwater, watershed applications. Application of the proposed methodology to large scale and unsteady hydrodynamic model, as observed for estuaries, is still rare (Dung et al. 2011) due to the 
101

required computational resources. The automatic calibration of physical coefficients looks for solution of an inverse problem. This solution corresponds to the minimization of the error

103 between the experimental results (field data) and the results estimated by a numerical model 104 (called direct model). To solve this inverse problem, two different methods have been 105 proposed (Fletcher, 1980-1981; Holland, 1975): gradient-based and meta-heuristic methods. 106 The first category uses the objective function gradient to search for the optimum, while the 107 second randomly searches for the optimum in a set of solutions (called the population of 108 individuals). The gradient-based methods require that the objective function satisfies 109 methods have the advantage of: (i) they are based on a random search and are therefore able

116 to explore the whole space of the solution; (ii) the objective function does not have to be 117 continuous allowing an efficient search for discrete problems, and (iii) they are robust, 118 offering the guarantee of convergence towards the global optimum. However, these methods 119 have the disadvantage of been computational costly at reaching the optimum since they are 120 based on an iterative procedure with slow convergence (Rudolph, 1994; Smaoui et al. 2018121 2019). In Geosciences, several meta-heuristic methods have been proposed, e.g. instance 122 genetic algorithms (GA, Goldberg, 1989); simulated annealing (SA, Kirkpatrick et al., 1982); 123 particle swarm optimization (PSO, Eberhart and Kennedy, 1995); ant colony optimization 124 (ACO, Dorigo and Gambardella, 1997); cat swarm optimization (CSO, Ch and Tsai, 2007), 
125 differential evolution (DE, Storn and Price, 1997) and evolution strategy (ES, Baeck et al. $1262000 a, 2000 b)$

127 In the present study, the Covariance Matrix Adaptation Evolution Strategy (CMA-ES, Hansen 128 and Ostermeier 1996) is applied to the 2DH hydrodynamic model of the Gironde estuary. This 129 meta-heuristic algorithm is first performed on six hydrological events selected between April 130 and August 2015 with different flowrate values. The period was selected based on the 131 availability of storm surges information provided by Météo-France. From these tests, results 132 are analysed in term of accuracy and friction distribution. Finally, the robustness of the 133 methodology is assessed by considering the effect of the mesh discretization and the number 134 of friction zones.

\section{STUDY AREA}

The Gironde Estuary's width reaches $20 \mathrm{~km}$ at the mouth and decreases to $3 \mathrm{~km}$ downstream

the confluence of the Dordogne and the Garonne Rivers. The tidal range varies from $1.5 \mathrm{~m}$

138 during neap tides to $5.5 \mathrm{~m}$ during spring tides at the mouth. Both Dordogne and Garonne 139 contributions to the freshwater discharge are estimated to $35 \%$ and $65 \%$, respectively 140 (Sottolichio, 1999). Based on the bed composition, the estuary can be decomposed in 3 141 different zones comprising (i) a sandy facies in the estuary mouth; (ii) a mixed facies 142 dominated by mud along the central part and (iii) a fluvial estuary, in the most upstream parts, 143 characterised by the presence of sand, pebbles and gravels (Allen 1972). Fine suspended144 sediments observed in the Gironde Estuary compose a pronounced Turbidity Maximum Zone 145 (TMZ) with concentrations ranging between 1 and $20 \mathrm{~g} / \mathrm{l}$ (Sottolichio and Castaing, 1999). Its 146 location along the estuary depends on hydrological conditions (Castaing, 1981; Jalón-Rojas, 147 2015). 
148 For the year 2015, a harmonic analysis (Pawlowicz et al., 2002) on measured water levels is

149 performed month by month at Verdon (mouth), Pauillac (central part) and Bordeaux (Port)

150 tidal gauge stations (Fig. 1). Variations of the $M_{2}$ amplitude according to the monthly averaged

151 discharge at previous stations are illustrated on Fig. 2.

152 At the mouth, a slight increase of the $M_{2}$ amplitude from 1.44 to $1.53 \mathrm{~m}$ with the flowrate is

153 observed. In the central part of the estuary, the $M_{2}$ amplitude increases progressively until a

154 relatively constant value. Conversely, the $\mathrm{M}_{2}$ amplitude tends to decrease at Bordeaux when

155 flowrate is increasing from 400 to $1200 \mathrm{~m}^{3} / \mathrm{s}$. A maximum value is reached around $300 \mathrm{~m}^{3} / \mathrm{s}$.

156 For the lowest flowrate values, $\mathrm{M}_{2}$ amplitude is then also decreasing probably due to a

157 migration of the turbidity maximum further upstream Bordeaux in the Garonne River (Jalón-

158 Rojas et al. 2018).

159 MATERIALS AND METHODS

160 Hydrodynamic model

161 The hydrodynamics is computed by a two-dimensional formulation based on the solution for

162 the depth-averaged shallow water equations (Eq. 1), with appropriate initial and boundary

163 conditions:

164

$$
\frac{\partial h}{\partial t}+\frac{\partial(h U)}{\partial x}+\frac{\partial(h V)}{\partial y}=0
$$

$$
\frac{\partial U}{\partial t}+\frac{\partial(U U)}{\partial x}+\frac{\partial(U V)}{\partial y}=-g \frac{\partial Z}{\partial x}+\frac{1}{h} \frac{\partial}{\partial x}\left(h v \frac{\partial U}{\partial x}\right)+\frac{1}{h} \frac{\partial}{\partial y}\left(h v_{t} \frac{\partial U}{\partial y}\right)-\frac{g}{h} \frac{1}{K^{2} h^{\frac{1}{3}}}\|\vec{U}\| U+S_{x}
$$

$$
\frac{\partial V}{\partial t}+\frac{\partial(U V)}{\partial x}+\frac{\partial(V V)}{\partial y}=-g \frac{\partial Z}{\partial y}+\frac{1}{h} \frac{\partial}{\partial x}\left(h v \frac{\partial V}{\partial x}\right)+\frac{1}{h} \frac{\partial}{\partial y}\left(h v_{t} \frac{\partial V}{\partial y}\right)-\frac{g}{h} \frac{1}{K^{2} h^{\frac{1}{3}}}\|\vec{U}\| V+S_{y}
$$


168 where $h$ is the water depth [m], $\vec{U}$ is the depth-averaged flow velocity vector $[\mathrm{m} / \mathrm{s}]$, with east-

169 west, north-south components $U$ and $V$, respectively, $\|\vec{U}\| \|$ is the velocity norm, $g$ is the 170 gravity acceleration $\left[\mathrm{m}^{2} / \mathrm{s}\right], Z$ is the free surface elevation [m], $v_{t}$ is the momentum diffusion 171 coefficient $\left[\mathrm{m}^{2} / \mathrm{s}\right], \rho$ is the water density $\left[\mathrm{m}^{3} / \mathrm{kg}\right], K$ is the Strickler-Manning coefficient $172\left[\mathrm{~m}^{1 / 3} / \mathrm{s}\right]$, Sx and Sy are additional source terms. The Strickler coefficient used for the bed 173 friction is just the inverse of the Manning coefficient. The mathematical system is therefore 174 composed of 3 equations and 5 unknowns $(h, U, V, K$ and $v$ ). Bed friction and diffusion 175 coefficients ( $\mathrm{K}$ and $v$ ) are provided by additional closure relationships or imposed values. A 176 constant value equal to $1 \mathrm{~m}^{2} / \mathrm{s}$ is imposed for the diffusion coefficient over the whole 177 numerical domain. In the shallow water equations, the bed friction term is included in the 178 source term of the momentum equation.

179 The module TELEMAC-2D of the TELEMAC-MASCARET modelling system (Hervouet 2007) is 180 applied in this study to solve the shallow water equations (Eq. 1), with the finite element 181 method. The computational domain is comprised from $30 \mathrm{~km}$ offshore the estuary mouth to $182180 \mathrm{~km}$ landward up to the limit of the tidal dynamic and extends to $20 \mathrm{~km}$ from the North to 183 the South (Fig. 1). The mesh is unstructured and composed of triangular elements. Two 184 different meshes with different element size resolutions are used in this work: the mesh 1 185 containing 28000 nodes and the mesh 2 containing 76000 nodes (Fig. 3). The distance 186 between nodes of mesh 1 ranges within $1000-2000 \mathrm{~m}$ offshore $300 \mathrm{~m}$ in the central part 187 (Fig.3a), and within 75-200 $\mathrm{m}$ in the tributaries (Fig. 3c). Mesh 2 features an enhanced 188 resolution along the navigation channel: within 300-2000 m offshore, within $60-300 \mathrm{~m}$ in the central part (Fig.3b) and within 33-100m upstream the confluence of both tributaries (Fig. 3d). 
191 At the maritime boundary, astronomic tide elevation and tidal currents are reconstructed 192 using NEA tidal atlases (North East Atlantic, Pairaud et al 2008, Huybrechts et al 2012) as a 193 superposition of harmonic waves (Schureman 1958) for each of the nodes of the offshore boundary (Eq. 2).

195

$$
H_{\text {tide }}=H_{0}+d H_{0}(t)+\sum_{n} H_{n} f_{n} \cos \left(\sigma_{n} t-g_{n}+V_{n}-u_{n}\right)
$$

where $\mathrm{H}_{\text {tide }}=$ the tidal height; $\mathrm{H}_{\mathrm{o}}=$ the mean height of the water level; $\mathrm{n}=$ the harmonics

number; $H_{n}=$ the mean amplitude of the $n$-wave; $f_{n}=$ the nodal correction for the

amplitude; $\sigma_{n}=$ the frequency; $t=$ the time; $g_{n}=$ the phase lag of the equilibrium tide; $V_{n}=$

the astronomic argument; and $u_{n}=$ the nodal correction for the phase lag. $\mathrm{dH}_{0}$ is the storm surge contribution.

Sea levels variation due to storm surges are applied to the tidal signal to improve water level predictions. Storm surge data are provided by a Météo-France model and computed every 10 minutes at 12 nodes located along the maritime boundary. Linear interpolation is then performed to incorporate surge values for each boundary node. In the previous study, Huybrechts et al (2012) decomposed the bed friction into 4 different zones delineated as:

208 mouth, central part and tributaries. In the present work the number of zones is firstly increased up to 7 zones $K_{i}$, (Fig. 1b) to better characterize the bed roughness of the estuary's tributaries. Finally, a configuration accounting for two additional friction zones located at the

211 central part of the estuary is considered (Fig. 1c). The delineation between the mouth and the 212 central part of the estuary (respectively zone 1 and zone 2, Fig. 1b) corresponds to a change 
213 in the bed material from sand to mud, respectively. Other remaining delineations are

214 arbitrarily defined mainly based on the geometrical features of the water body.

\section{Optimization algorithm}

216 The optimization algorithm implemented in this work is based on the evolutionary strategy

217 algorithm (ESA, Baeck et al. 2000a, 2000b, Dréo et al. 2005). According to the Darwin's theory, 218 evolution will produce at the long-term organisms more adapted to their environment (Dréo 219 et al. 2005). Thus, in order to achieve better results, ESAs evolve in a set (called population) of 220 solutions (called individuals) and a searching root on a random population instead of an 221 individual. Research on a population increases the probability to find the optimum among 222 individuals. During the iterative process (called generation) leading to the optimal solution, 223 the populations evolve according to selection and variation cycles. From the ESA family, we 224 have adopted the CMA-ES algorithm. This algorithm, due to Hansen and Ostermeier (1996), 225 has been proposed to improve several aspects of the others ESA but specially to overcome 226 the main issues of the optimization solvers based on genetic algorithms (Espana et al 2017). 227 CMA-ES offers good performance in optimizing functions that are not regular enough or even 228 undefined explicitly. The CMA-ES research space has the advantage of evolving real numbers 229 set, thus avoiding the coding/decoding steps that characterize the genetic algorithms (GA). 230 However, a complete description of the CMA-ES is out of the present scope. It is worth noting 231 that metaheuristic optimization methods such CMA-ES can be effectively coupled with other 232 numerical models to identify some parameters model not accessible from measurements 233 (Bayer and Finkel, 2004; Elshall et al. 2015; Smaoui et al. 2018 and Smaoui et al., 2019). 234 Additional details are provided in the Appendix whereas full descriptions of the algorithm are 
235 available in Hansen and Ostermeier (2001); Hansen et al. (2003), Dréo et al. (2005) or Hansen 236 (2006 \&2016).

\section{Coupling between the hydrodynamics module and the optimization algorithm}

238 The coupling interface between the optimization algorithm (CMA-ES) and the hydrodynamic 239 module (TELEMAC-2D) is performed with the multi-paradigm numerical computing 240 environment and proprietary programming language Matlab $\subset$, developed by MathWorks 241 (Moler and Little 2020). The specificity of each application relies on the way of building the objective function. In our application involving 2D hydrodynamic modelling, the unknowns are

243 the values of the different bed friction coefficients and the variable to optimize is the 244 difference between measured and computed water levels. The coupling flowchart between 245 the hydrodynamics module and the optimization algorithm is illustrated on Fig. 4.

246 An initial distribution of the bed friction coefficient is provided. A steering subroutine is 247 implemented to build the objective function. This subroutine calls the module TELEMAC-2D 248 for launching the numerical simulations, it post-processes the numerical results and it 249 evaluates the RMSRE (Root Mean Square Relative Error, Eq .4) between the computed water 250 level depending on the friction distribution (Zc, Fig. 4) and the measurement (Zm, Fig. 4). The 251 RMSRE is estimated at 8 tidal gauge stations (Fig. 1): Verdon, Laména, Pauillac, Medoc, Ambes, 252 Bordeaux, Cadillac, Libourne. The first six stations are located along the navigation channel. 253 Cadillac station located more upstream in the Garonne River, while Libourne station located 254 in the Dordogne River.

255 The CMA-ES algorithm searches for minimizing the mean value of the RMSRE of the 8 stations. 256 The minimized value is referred as RMSREm ( $\mathrm{m}$ for mean between the 8 stations). For each 257 station, the RMSRE is computed by (Eq. 3): 


$$
R M S R E=\frac{\sqrt{\frac{1}{n} \sum_{i=1}^{n}\left(Z_{m i}-Z_{c i}\right)^{2}}}{Z_{m}}
$$

261 Where $Z_{m i}$ is the measured water levels [m] at a gage station and $Z_{c i}$ is the computed values, $n$ 262 the number of " $i$ " observations and $Z_{m}$ the mean measured value.

\section{RESULTS}

\section{Convergence of the algorithm depending hydrological conditions}

265 Six hydrological events are selected from April to August 2015 with flowrate varying from 150 to $1300 \mathrm{~m}^{3} / \mathrm{s}$ in the Garonne River and from 200 to $1500 \mathrm{~m}^{3} / \mathrm{s}$ in the central part considering the Dordogne contribution. Each event is simulated with 500 runs covering a period of 6 days.

268 The same initial friction distribution defined from Huybrechts et al (2012) is applied to all 269 configurations. The configuration with 7 friction zones is firstly tested. The evolution of the 270 mean error for the 8 stations during the optimization procedure is illustrated on Fig. $5 a$ for the 271 four events from April to June. Similar evolutions are also plotted on Fig. 5b for Pauillac station.

272 As shown in Fig 5 a most of the gain is reached within the first 250 runs. The accuracy gain is 273 more evident with the evolution of the relative error at Pauillac station (Fig. 5b). RMSRE starts 274 around 0.18 , then it is decreasing down to lower than 0.1 and it may even reach 0.06 (Fig. 5b). 275 At Pauillac for a mean tidal range of $1.6 \mathrm{~m}$, a decrease of $12 \%$ in relative error coincides with 276 an absolute gain of $0.19 \mathrm{~m}$. The results with 7 zones (Fig $1 \mathrm{~b}$ ) are summarized in Table 1. 
Relative error is within the range [0.14 - 0.18] before optimization and [0.09 - 0.12] after

278 optimization (Table 1, Fig. 5a). The global gain is thus within 3 and $8 \%$ and the accuracy gain

279 is increasing with the flowrate. For the 6 hydrological configurations, the mean ratio between

280 final and initial error is 0.7 . Along the different station, the mean ratio is almost equal to 1 at

281 Verdon, between 0.51 and 0.59 at Laména, Pauillac and Medoc and within 0.73-0.84 at

282 Ambes, Bordeaux, Cadillac and Libourne. At Verdon, no accuracy gain is observed. It might

283 suggest that improving the accuracy at Verdon through bottom friction coefficient leads to

284 deteriorate the accuracies of the other upstream stations. Improvement at the mouth may

285 probably require enhanced offshore boundary conditions which is a combination of tidal

286 atlases (Huybrechts et al 2012) and prediction of the storm surges. Less accuracy gain could

287 also be expected at the uppest estuarine part due to a sparse bathymetry dataset. However,

288 for an application related to ship route and underkeel clearance management inside the

289 estuarine configuration (Orseau et al., 2020b), it is crucial to attain an efficient prediction of

290 water levels at the central part where navigable depths are more restricted.

291 Variation of the bed friction distribution related to the flowrate

292 The algorithm allows to reach a mean error relatively constant for the different hydrological

293 conditions. Nonetheless, it requires for each case an adaptation of the values for bed friction

294 coefficient. As suggested in Fig. 2, the flowrate variation might be responsible of the TM

295 migration of the fluid mud deposits, and it thus has an influence on the bottom roughness.

296 Friction coefficients are plotted as a function of the flowrate to find a relationship that could

297 be used to set an operational model. It is performed on Figs. 6 for the distribution with 7

298 friction zones. The zones are gathered as downstream part of the estuary for K1 and K2 (Fig.

299 6a), as Dordogne river for K3 and K4 (Fig. 6b) and as Garonne river for K5-K6 and K7 (Fig. 6c). 
300

301 observed between evolution of $\mathrm{K} 2$ and $\mathrm{M}_{2}$ amplitude at Pauillac.

303

For the Dordogne river (Fig. 6b), a parabolic distribution is obtained for $\mathrm{K} 3$ and a third 304

The optimized distribution of bed friction obtained on a 28000 nodes is assessed on a finer grid resolution (76000 nodes). The finer mesh is characterized by a better resolution along the

The evolution of the $\mathrm{K} 1$ coefficient (mouth, Fig. 6a) is in agreement with the evolution of $\mathrm{M}_{2}$ amplitude in Verdon: slight linear increase according to the flowrate. Similar patterns are also polynomial curve accurately describes the K4 evolution. For the Garonne river (Fig. 6c), K5 and

K6 describe a second order decreasing curve according to the flowrate. It means that the friction increases due to the seaward migration of the TM which is in line with $M_{2}$ evolution at Bordeaux. Similarly, for the lowest flowrates, the friction coefficient seems to reach a maximum value as observed with $\mathrm{M} 2$ amplitude. The most upstream coefficient $\mathrm{K} 7$ describes an inverse behaviour with maximum value around $700 \mathrm{~m}^{3} / \mathrm{s}$. The plotted regression curves show the general tendencies of the friction evolution. Nonetheless, extrema values for $\mathrm{K} 5$ and K6 are not well captured by the simple second order equations. For the operational model, it would be rather suggested to use piecewise linear equations between the 6 optimized values.

\section{Applicability of the methodology to finer mesh discretization and friction distribution}

The proposed methodology requires between 250-500 TELEMAC-2D runs to reach the optimized friction distribution. For a 12 cores of $2.4 \mathrm{GHz}$ RAM 48 Go workstation, 500 runs are performed in approximately one-day wall-clock time. Computational efficiently can be gained by avoiding some repetitive steps inside each individual run, by reducing the number of runs or by increasing the computing resources. Nevertheless, alternative way can be suggested to avoid a rough application of the methodology to a finer mesh.

\footnotetext{
navigation channel and upstream the confluence. Table 2 summarises the averaged RMSRE at
} 
each station along the navigation channel obtained with the 6 hydrological events after an optimization of the coarser mesh. It reaches values ranging from $7.7 \%$ (Pauillac) to $13 \%$ (Bordeaux) with a mean value of $9.8 \%$. Direct application of the optimized values to the finer grid leads to RMSE within 6.9 to $11 \%$ with a mean value of $8.7 \%$. It means that the optimized values and associated abacuses are also valid on this finer mesh. As an alternative, the optimized value obtained from the coarse mesh could be used as initial solution for a second optimization with a finer mesh and a shorter number of runs.

To address the sensitivity to the number of friction zone, the optimization methodology is applied to the same 6 hydrological events, but with 9 zones (Fig. 1c) on Mesh 1. As detailed in Table 1, no significant differences can be noticed in term of accuracy. However, the values of the friction distributions are different in the central part. To distinguish the friction zone between the methodologies accounting for 7 or 9 zones, friction coefficients for the 9 zone distributions are noted as KK1 to KK9. In fact, K2 extension covers the area sum of KK2, KK3 and KK4 whereas KK1 is the same zone as K1. The evolution of the bed friction coefficients in the central part is shown in Fig. 7.

KK1 describes a linear relationship whereas KK2 and KK3 describe a parabolic relationship with a maximum value around $800-900 \mathrm{~m}^{3} / \mathrm{s}$. KK4 rather describes a parabolic relationship with a minimum value. It should be noted that KK1 is smaller than K1 and KK2 higher than K2. It results in a more abrupt transition occurring between the two zones which may affect the numerical results if the model is coupled to a sediment transport and bed evolution module.

\section{Application of time-varying friction coefficients to a medium-term simulation (6 months).}

From Fig. 6, a relationship can be built between the friction coefficient and the flowrate for all the 7 friction zones. Concerning the regression, piecewise linear relationships are selected to 
interpolate the values for all flowrate values. Three simulations are conducted from April $1^{\text {st }}$

347 to the end of October 2015. The first two simulations are based on steady friction coefficients

348 extracted from the optimization step. The first one corresponds to friction coefficient 349 representative of low flowrate configuration $\left(200 \mathrm{~m}^{3} / \mathrm{s}\right)$ and the second one rather 350 corresponds to a configuration representative of mean discharge configuration $\left(800 \mathrm{~m}^{3} / \mathrm{s}\right)$.

351 The last and third simulation tests the piecewise linear relationships (PWL).

352 Time series of storm surges and flowrate are imposed at the boundary conditions. The time 353 step of flowrates is equal to 2 hours whereas it is equal to $10 \mathrm{~min}$ for the storm surge. Flowrate 354 ranges within 130 and $2700 \mathrm{~m}^{3} / \mathrm{s}$ during this period. At Verdon, Pauillac and Bordeaux, the 355 RMSRE are evaluated every two tidal cycles (25 hours) to provide an averaged estimation of 356 the accuracy. Values of RMSRE at Bordeaux and Pauillac stations are plotted in regards to 357 flowrate also averaged every 25 hours. At the Verdon station, the accuracy for each simulation 358 is equivalent (not showed here).

359 For the simulation 2 referred as "mean", the values of friction coefficients are not suited for 360 low flowrates. The RMSRE can increase up to more than $20 \%(>30 \mathrm{~cm})$ at Pauillac. A similar 361 behaviour is observed at Bordeaux. In contrast, for the simulation 1 referred as "Low", the 362 accuracy tends to decrease at Pauillac once values are higher than $500 \mathrm{~m}^{3} / \mathrm{s}$, while, at 363 Bordeaux, the accuracy is more variable. However even if the prediction is correct at 364 Bordeaux, the accuracy is not sufficient in the central part. The advantage of the PWL 365 simulation is to maintain a constant accuracy for a wider range of flowrate since it combines 366 the advantage of the two previous simulations. 
368 The CMA-ES algorithm has been coupled to the hydrodynamic module TELEMAC-2D applied 369 to optimize the distribution of the bed friction coefficient inside the Gironde estuary. For the 370 tested configuration, 300 runs seemed to be sufficient to reach an optimal value. Additional 371200 runs would help to gain an accuracy of few millimetres (or $0.3 \%$ ). For simulations 372 performed on a 12 core workstation), 500 runs are completed in approximately one-day wall373 clock time for 12 tidal cycles. The application of the proposed methodology shows that it is 374 necessary to modify the bed friction coefficient in order to reach the same level of accuracy 375 for the different hydrological configurations. It also confirms a seasonal variation of the 376 friction coefficient and this particularly in the central part of the estuary. Different 377 relationships of the friction coefficient according to the flowrate have been incorporated 378 inside the operational model. These relationships effectively allow to maintain an accurate 379 prediction of the water levels for a wide range of hydrological configurations. However, 380 further investigations on more extreme events, such as flood, storm and long dry periods, are 381 still needed to provide more robust bed friction relationships.

382 For operational models, it would be interesting to further apply the methodology with several 383 flow configurations in order to build a surrogate model providing the friction distribution 384 according to hydro-meteorological forcing (flowrate, tidal range, storm surge) and to compare 385 such variation to data related to the bed texture or water column as bed sample or satellite 386 images of suspended matters. 
Data, models, and code scripts used for coupling CMA-ES and TELEMAC-2D developed in this study are available from the corresponding author upon request. Water levels data are available at www.vigicrues.gouv.fr.

\section{1}

392

401

402

$K=$ Strickler coefficient for the bed friction in $\left[\mathrm{m}^{1 / 3} / \mathrm{s}\right]$

404 RMSRE $=$ Root Mean Square Relative Error [-]

\section{ACKNOWLEDGMENTS} results.

\section{NOTATIONS}

$\mathrm{g}=$ gravity acceleration $\left[\mathrm{m} / \mathrm{s}^{2}\right]$;

$h=$ water depth in $[\mathrm{m}]$;

The research leading to these results has received funding from the Connecting Europe Facility (CEF) - Transport Sector under agreement (Innovation and Networks Executive Agency) No INEA/CEF/TRAN/M2014/1049680 through the project Gironde XL. The authors thank the National Hydrographic Service (SHOM) and the National Weather Agency (Météo-France) for providing bathymetric datasets, and predictions of tide-surge interactions. Dr. Tom Benson is kindly acknowleged for providing the Matlab toolbox used to post-processTELEMAC-2D

$\vec{U}=$ depth-averaged flow velocity vector, with east-west $\mathrm{U}$, north-south $\mathrm{V}$ components $[\mathrm{m} / \mathrm{s}]$. 
$v_{t}=$ momentum diffusion coefficient $\left[\mathrm{m}^{2} / \mathrm{s}\right]$

408

$\rho=$ density $\left[\mathrm{m}^{3} / \mathrm{kg}\right]$

409

\section{APPENDIX: BRIEF DESCRIPTION OF THE CMA-ES ALGORITHM}

411 CMA-ES is a meta-heuristic optimization algorithm. It belongs to the class of algorithms called

412 "Evolution Strategies". The research step of these algorithms is carried out in a stochastic way 413 without any gradient calculation. The CMA-ES algorithm operates on a population of 414 individuals rather than on a single individual (as in the case of gradient algorithms).

415 Like all meta-heuristic algorithms, CMA-ES starts from an initial population randomly chosen.

416 To build a new generation of individuals, the CMA-ES algorithm follows on from the selection

417 step in which the new candidate solutions are sampled using a multivariate normal 418 distribution. Then individuals of this generation are evaluated via the objective function and 419 selected according to their fitness (or objective function value) to be part of the next 420 generation. Then comes the recombination stage to select a new mean value for the 421 distribution. The penultimate step of the CMA-ES algorithm is the mutation which consists in 422 adding a random vector acting as a perturbation with zero mean. The adaptation step 423 terminates the algorithm by updating the various parameters involved in the construction of 424 the covariance matrix. From this brief description of CMA-ES algorithm, we conclude that it is

425 the mutation and adaptation stages that make this algorithm a robust and powerful tool for 426 complex numerical optimization. In order to not burden the text and given their importance, 427 we will briefly describe these two stages. 
The mutation is a step in the CMA-ES algorithm which allows generation of a new population

431 with the aim of improving the one generated by the selection and recombination steps. It is certainly the most important step in the algorithm. It adds a random vector deduced from the multivariate distribution based on the previous generation (selection and recombination). The 434 mutation guides CMA-ES to move in the search space by rotation and by scaling the adapted 435 covariance matrix of the generated population. The evolution of this iterative process is 436 controlled by different parameters (called strategy) which update automatically from 437 information from previous generations. This process is called "evolution path". It's this 438 automatic parameter update that makes this algorithm the most powerful in its class. The user 439 does not set any parameters for the correct execution of the algorithm.

440 As explained above, the ES algorithms are considered to be slow to converge towards the 441 global optimum. To accelerate this convergence, the CMA-ES algorithm offers an intermediate 442 recombination which averages a few vector individuals from the parent population. This 443 combination is noted by $\left(\frac{\mu}{\mu_{I}}, \lambda\right)$-CMA-ES where $\left(\frac{\mu}{\mu_{I}}\right)$ designates the recombination of $\mu_{I}$ 444 among $\mu$ parents and $\lambda$ is the number of individuals in the initial population. Thus, for the 445 algorithm $\left(\frac{\mu}{\mu}, \lambda\right)$-CMA-ES the $\lambda$ individuals of the generation $(g+1)$ are calculated by:

$$
p_{i}^{(g+1)}=\langle p\rangle_{\mu}^{(g)}+\sigma^{(g)} N\left(0, C^{(g)}\right), \quad i=1, \ldots . \lambda
$$

448 With $p_{i}^{(g+1)}$ is the ith individual of the population of the generation $(g+1),\langle p\rangle_{\mu}^{(g)}$ is the 449 mean value of $p^{(g)}$ at generation $(g)$ computed by

$$
\langle p\rangle_{\mu}^{(g)}=\frac{1}{\mu} \sum_{k=1}^{\mu} p_{k}^{(g)}
$$


$451 \sigma^{(g)}$ is the standard deviation at generation $(g)$ (but for CMA-ES, it is also called step size),

$452 N\left(0, C^{(g)}\right)$ note the normal distribution with center 0 and covariance $C^{(g)}$ at generation $(g)$.

453 It should be noted that the covariance matrix is a symmetric definite positive matrix, therefore

454 diagonalizable. In this case the covariance matrix $C^{(g)}$ can be written as:

455

$$
C^{(g)}=B^{(g)} D^{(g)}\left(B^{(g)} D^{(g)}\right)^{T}
$$

456

457

458

459

460

461

462

463

464

465

466

467

468

469

470

471
Eq. 5

Where the columns of the matrix $B^{(g)}$ are exactly the eigenvectors of $C^{(g)}$ and $D^{(g)}$ is a diagonal matrix whose diagonal elements are the square root of the eigenvalues of $C^{(g)}$. The combination of expressions (1) and (2) allows to rewrite (1) in the new form as:

$$
p_{i}^{(g+1)}=\langle p\rangle_{\mu}^{(g)}+\sigma^{(g)} B^{(g)} D^{(g)} z_{i}, \quad i=1, \ldots . \lambda
$$

Eq. 6

With $z_{i}=\left(B^{(g)} D^{(g)}\right)^{T} N(0, I), \quad i=1, \ldots \ldots \lambda$

Finally, the calculation of the covariance matrix at generation $(g+1)$ is based on the calculation of the evolution of the path $p_{t}$ at generation $(g+1)$ according to the following scheme:

$$
p_{t}^{(g+1)}=(1-c) \cdot p_{t}^{(g)}+c_{u} \frac{\sqrt{\mu}}{\sigma^{(g)}}\left(\langle p\rangle_{\mu}^{(g+1)}-\langle p\rangle_{\mu}^{(g)}\right)
$$

$$
C^{(g+1)}=\left(1-c_{\operatorname{cov}}\right) \cdot C^{(g)}+c_{\operatorname{cov}} p_{t}^{(g+1)} \cdot\left(p_{t}^{(g+1)}\right)^{T}
$$

Eq. 8

472 Where $\frac{1}{c}$ is the cumulative time of the evolution path. The parameter $c$ can be interpreted a

473 weight allowing the smoothing of $p_{t}$ and can be normalized by $c_{u}=\sqrt{c(2-c)} \cdot \frac{1}{c_{c o v}}$ denotes 


\section{BIBLIOGRAPHY}

Allen, G.P., (1972). Etude des processus sédimentaires dans l'estuaire de la Gironde. PhD Thesis, University of Bordeaux I, 310.

Baeck, T. Fogel D. B. and Michalewicz Z. (2000a). Evolutionary Computation 1 : Basic Algorithms and Operators, Institute of Physics Publishing.

Baeck T., Fogel D. B. and Michalewicz Z. (2000b). Evolutionary Computation 2 : Advanced Algorithms and Operators, Institute of Physics Publishing, 2000b

Bayer and Finkel, 2004: Evolutionary algorithms for the optimization of advective control of contaminated aquifer zones. Water Resour. Res. 40, W06506, doi:10.1029/2003WR002675

Castaing, P., (1981). Le transfert à l'océan des suspensions estuariennes - Cas de la Gironde. PhD Thesis, University of Bordeaux I, $530 \mathrm{p}$.

Ch, S.C. and Tsai, P.W. (2007). Computational intelligence based on the behavior of cats. International Journal of Innovative computing, information and control. Vol. 3(1), pp.163173.

Dorigo, M. and Gambardella, L.M. (1997): Ant colony system: a cooperative learning approach to the traveling salesman problem. IEEE Trans. on Evolutionary Computation 26(1), 5366.

Dréo, J., Pétrowski, A., Siarry, P., \& Taillard, E. (2005). Metaheuristics for hard optimization. Berlin Heidelberg, Germany: Springer-Verlag.

Dung, N. V., Merz, B., Bárdossy, A., Thang, T. D., and Apel, H. (2011) Multi-objective automatic calibration of hydrodynamic models utilizing inundation maps and gauge data, Hydrol. Earth Syst. Sci., 15, 1339-1354, https://doi.org/10.5194/hess-15-1339-2011

Eberhart, R. and Kennedy, J. (1995): A new optimizer using particle swarm theory. In: Sixth International Symposium on Micro Machine and Human Science, pp. 39-43

Elshall, A.S., Pham, H. V., Tsai, F.T.-C., Yan, L., Ye, M., 2015. Parallel Inverse Modeling and Uncertainty Quantification for Computationally Demanding Groundwater-Flow Models Using Covariance Matrix Adaptation. J. Hydrol. Eng. 20, 04014087

Espana, M., Hernández-Díaz, A.M., Cecilia, J.M. and García-Román, M.D. (2017). Evolutionary strategies as applied to shear strain effects in reinforced concrete beams:, Applied Soft Computing, vol 57, pp:164-176

Fletcher, R. (1980), Practical methods of optimization: Volume 1 constrained optimization, John Wiley \& Sons, New York, USA, $126 \mathrm{p}$.

Fletcher, R. (1981), Practical methods of optimization: Volume 2 unconstrained optimization, John Wiley \& Sons, New York, USA, 232 p. 
Goldberg, D.E.: Genetic Algorithm in Search. Optimization and Machine Learning. AddisonWesley Publishing Company (1989)

Hansen, N., \& Ostermeier, A. (1996). Adapting arbitrary normal mutation distributions in evolution strategies: The covariance matrix adaption. In Proceedings of the Third IEEE International Conference on Evolutionary Computation, IEEE Press, Nagoya (Japan), pp. 312-317.

Hansen, N., \& Ostermeier, A. (2001). Completely derandomized self-adaptation in evolution strategies. Evolutionary Computation, 9(2), 159-195.

Hansen, N. (2016). "The CMA Evolution Strategy: A Tutorial". https://arxiv.org/abs/1604.00772

Hansen, N. (2006). The CMA evolution strategy: a comparing review, in: Towards a New Evolutionary Computation, Springer, 2006, pp. 75-102.

Hervouet, J.M., (2007). Hydrodynamic of free surface flows modelling with the finite element method. Wiley ISBN 978-0-470-03558-0

Holland, J. H. (1975). Adaptation in natural and artificial systems: An introductory analysis with applications to biology, control, and artificial intelligence. U Michigan Press.

Huybrechts, N., Villaret, C. and Lyard, F., (2012). Optimized predictive 2D hydrodynamic model of the Gironde Estuary (France). Journal of Waterway, Coast, Port and Ocean engineering, $138(4), 312-322$.

Huybrechts, N., and Villaret, C., (2013). Large-scale morphodynamic modelling of the Gironde Estuary, France. Proceedings of the Institution of Civil Engineers in Maritime Engineering, 166 (2), 51-62.

Jalón-Rojas, I., Schmidt, S. and Sottolichio, A., (2015). Turbidity in the fluvial Gironde Estuary (southwest France) based on 10-year continuous monitoring: sensitivity to hydrological conditions, Hydrology and Earth System Sciences, (19), 2805-2819.

Jalon-Rojas, I., Sottolichio, A., Hanquiez, V., Fort, A., \& Schmidt, S. (2018). To what extent multidecadal changes in morphology and fluvial discharge impact tide in a convergent (turbid) tidal river. Journal of Geophysical Research: Oceans, 123. https://doi.org/ 10.1002/2017JC013466

Kirkpatrick, S.D. Gelatt, C. and Vecchi, M.P. (1982): Optimization by simulated annealing. IBM Research Report RC 9355, Acts of PTRC Summer Annual Meeting,.

Laborie, V., Hissel, F., and Sergent, P., (2014). Impact of climate change on Gironde estuary. La Houille Blanche, 6, 34-39.

Lane, S. N. (1998). Hydraulic modelling in hydrology and geomorphology: a review of high resolution approaches. Hydrological Processes, 12(8), 1131-1150.

Le Floch, J. (1961). Propagation de la marée dynamique dans l'estuaire de la Seine et la SeineMaritime. PhD thesis, Université de Paris. 507p.

Moldwin, M. (2016), Tidal river dynamics, Eos, 97, https://doi.org/10.1029/2018E0049541.

Moler C. and Little J. (2020). A history of MATLAB. Proc. ACM Program. Lang. 4, HOPL, Article 81 (June 2020), 67 pages. DOI:https://doi.org/10.1145/3386331 
Orseau, S., Huybrechts, N., Tassi, P., Pham Van Bang, D. and Klein, F. (2020a) Two-dimensional modeling of fine sediment transport with mixed sediment and consolidation: Application to the Gironde Estuary, France. International Journal of Sediment Research (in press).

Orseau S., Huybrechts N., Tassi P., Kaidi S., Klein F (2020b). Nav-Tel: an open-source system for ship routing and underkeel clearance management in estuarine channels. J. of Waterway Port Coastal Eng (In revision).

Pairaud, I.L., Lyard, F., Auclair, F., Letellier, T., and Marsaleix, P., (2008). Dynamics of the semidiurnal and quarter-diurnal tides in the bay of Biscay. Continental Shelf Research, 28(1011), 1294-1315.

Pawlowicz R., Beardsley B., and Lentz S., (2002). Classical tidal harmonic analysis including error estimates in MATLAB using T_TIDE. Computers and Geosciences, 28 (2002), 929-937.

Rudolph., G. (1994). Convergence analysis of canonical genetic algorithms. IEEE Transactions on Neural Networks, 5:96-101, 1994

Smaoui, H., Maqsoud, A., Kaidi, S. (2019), Transmissivity Identification by Combination of CVFEM and Genetic Algorithm: Application to the Coastal Aquifer. Mathematical Problems in Engineering, 3463607, 14 pages.

Smaoui H., Zouhri L., Kaidi S. (2018) Combination of FEM and CMA-ES algorithm for tranmissivity field identification in aquifer systems. Hyrdological Processes Journal. 32(2):264-277

Sottolichio, A., (1999). Modélisation de la dynamique des structurs turbides (bouchon vaseux et crème de vase) dans l'estuaire de la Gironde, PhD Thesis, University of Bordeaux I.

Sottolichio, A. and Castaing, P., (1999). A synthesis on seasonal dynamics of highlyconcentrated structures in the Gironde Estuary, Comptes Rendus de l'Académie des Sciences, 329, 795-800.

Sottolichio, A., Le Hir, P., and Castaing, P., (2001). Modelling mechanisms for the turbidity maximum stability in the Gironde Estuary, France. Coastal and Estuarine Fine Sediment Processes, 373-386.

Schureman, P. (1958). Manual of harmonic analysis and prediction of tides, US Department of Commerce, Coast and Geodetic Survey, Washington, DC.

Storn R. and Price K., (1997).Differential Evolution - A Simple and Efficient Heuristic for global Optimization over Continuous Spaces. Journal of global optimization. Vol 1, pp. 341-359

van Rijn L.C. (2007) Unified view of sediment transport by currents and waves. I: Initiation of motion, bed roughness, and bed-load transport, J. Hydraulic Eng. 133( 6), pp. 649-667

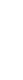


588

589

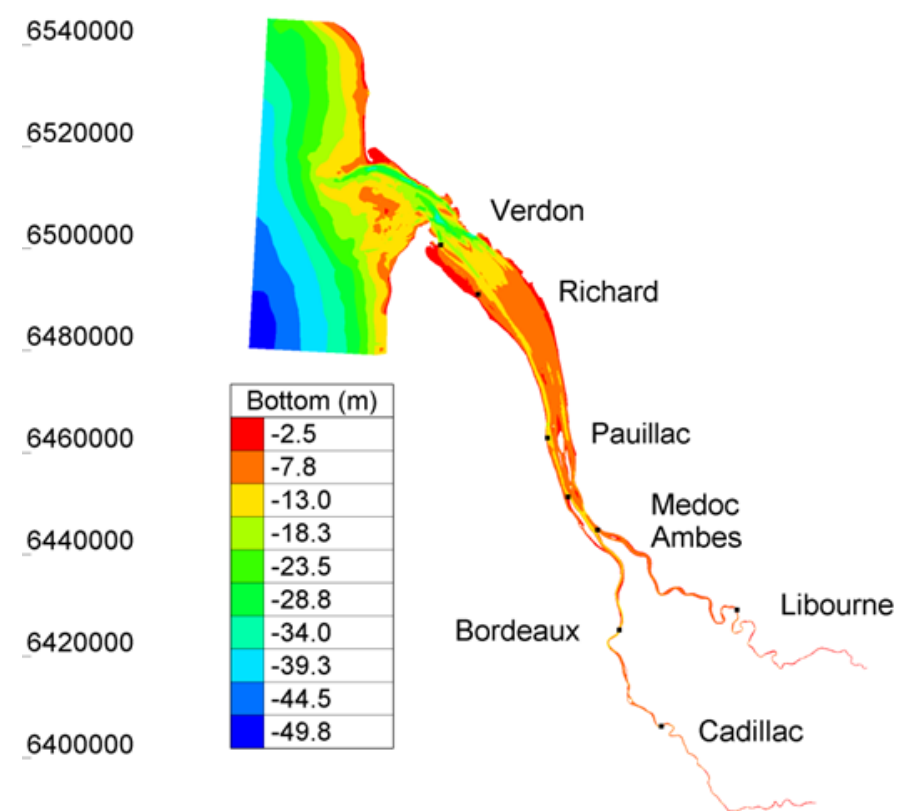

$32000034000036000038000040000042000044000046000 C$

$1 a$

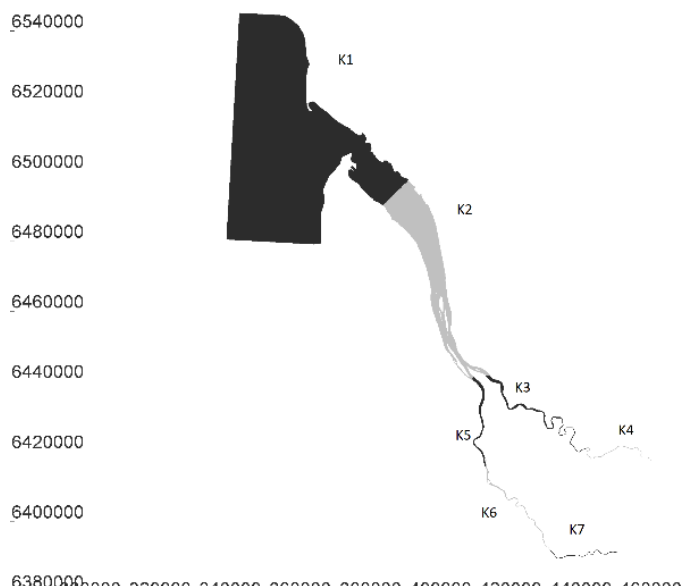

$1 b$

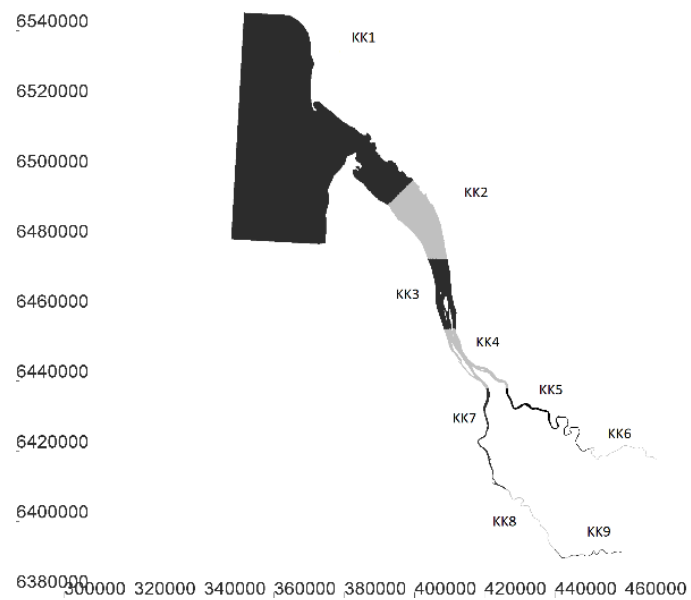

$1 c$ 


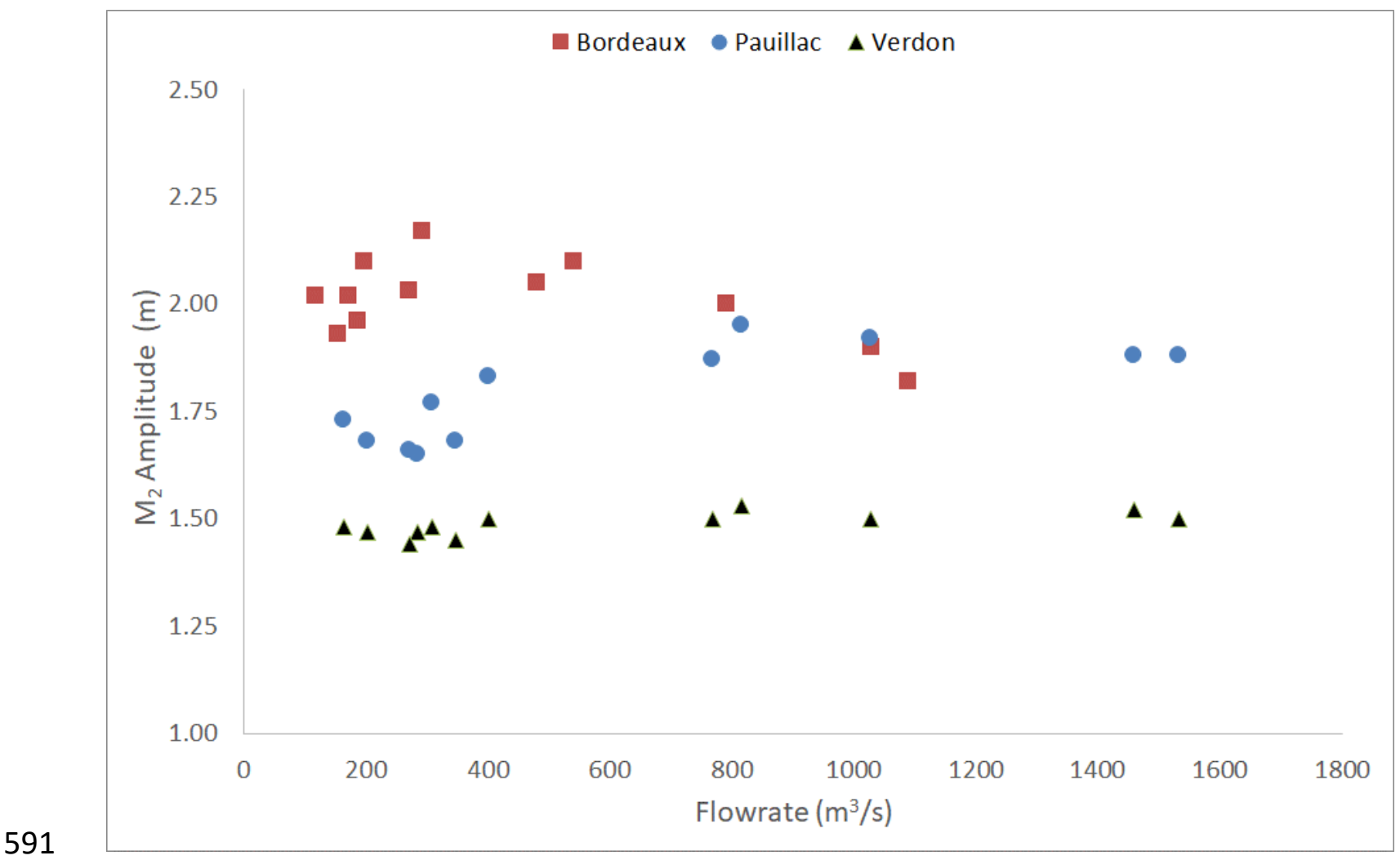

592 Figure 2 Seasonal variation of $\mathbf{M}_{2}$ amplitude with the total flowrate at Le Verdon, Pauillac station and with Garonne 593 flowrate at Bordeaux station (Fig. 1).

594

595

596

597 


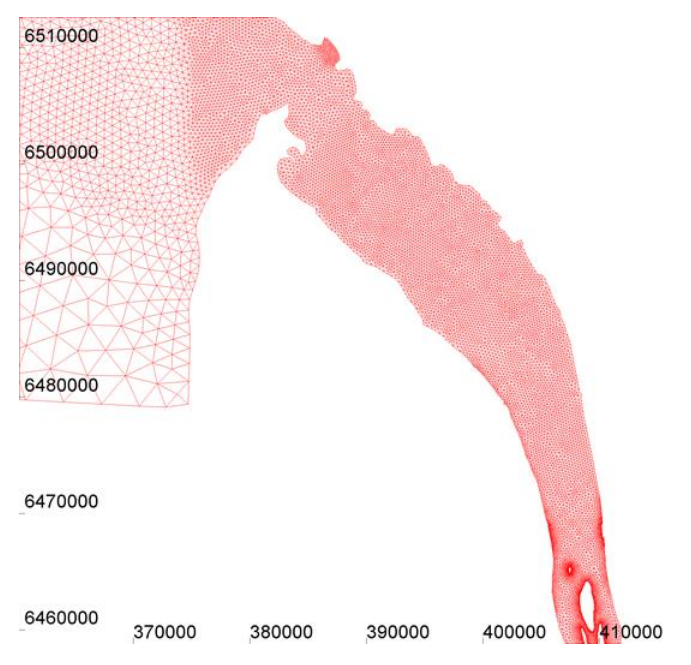

$3 a$

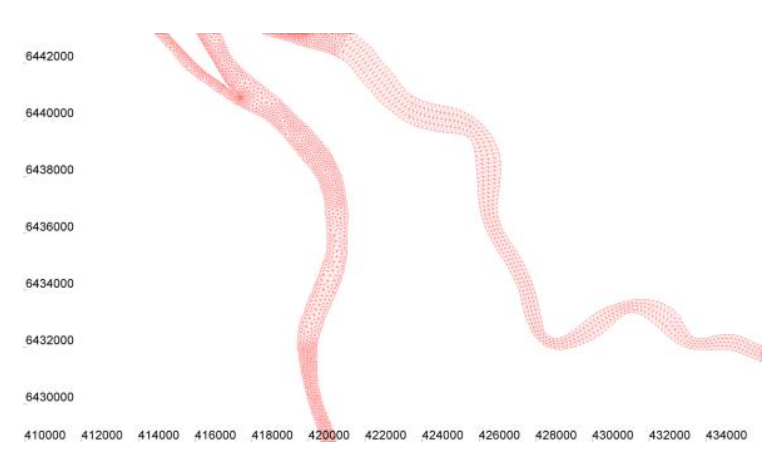

$3 c$

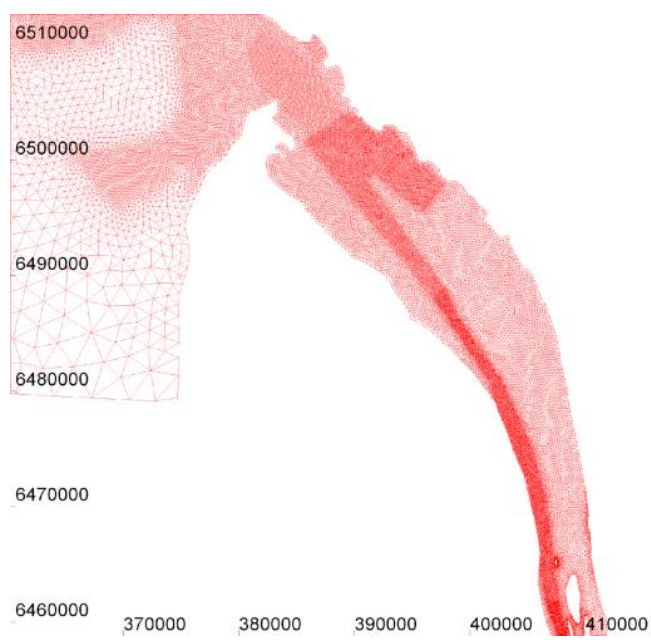

$3 b$

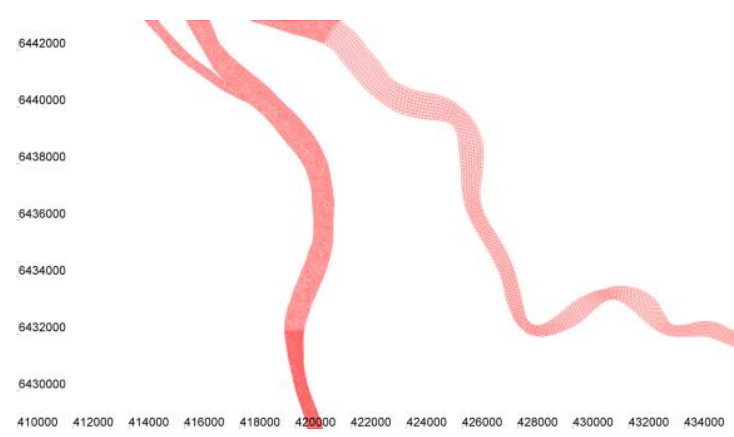

$3 d$

598 Figure 3 Mesh distribution: (3a) mesh 1 with 28000 nodes in the downstream area, (3b) mesh

5992 with 78000 nodes in the downstream area, (3c) mesh 1upstream the junction, (3d) mesh 2

600 upstream the junction.

601

602 


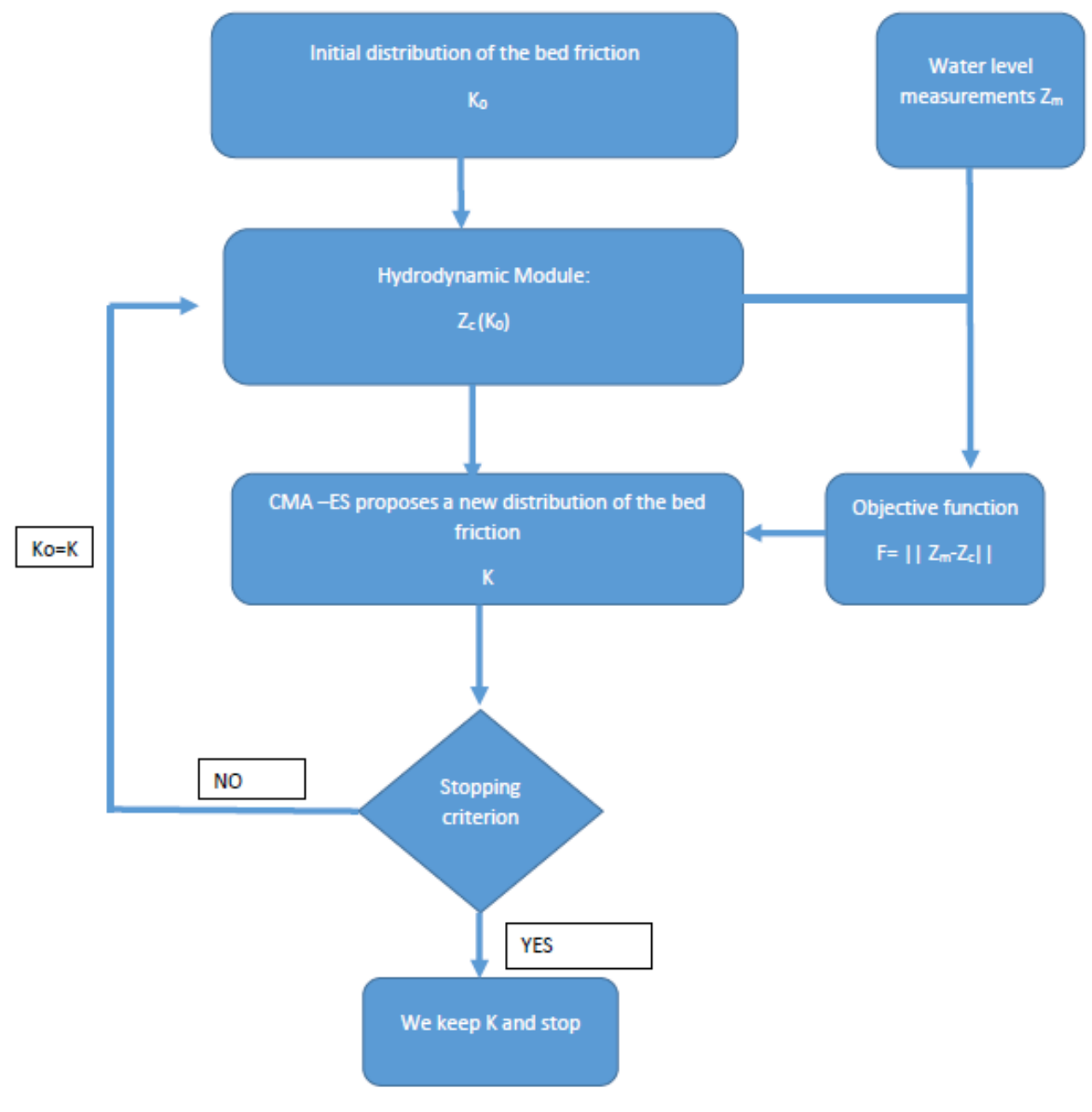

604 Figure 4 Flowchart of the coupling between the hydrodynamics module and the optimization algorithm 605

606

607

608 


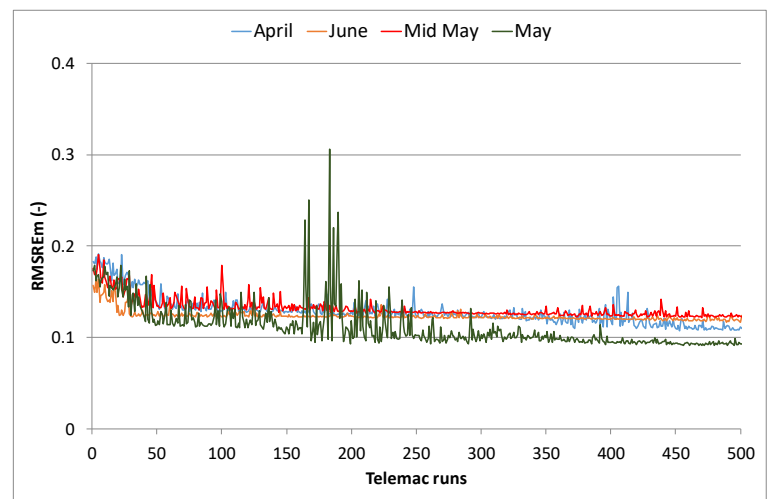

$5 a$

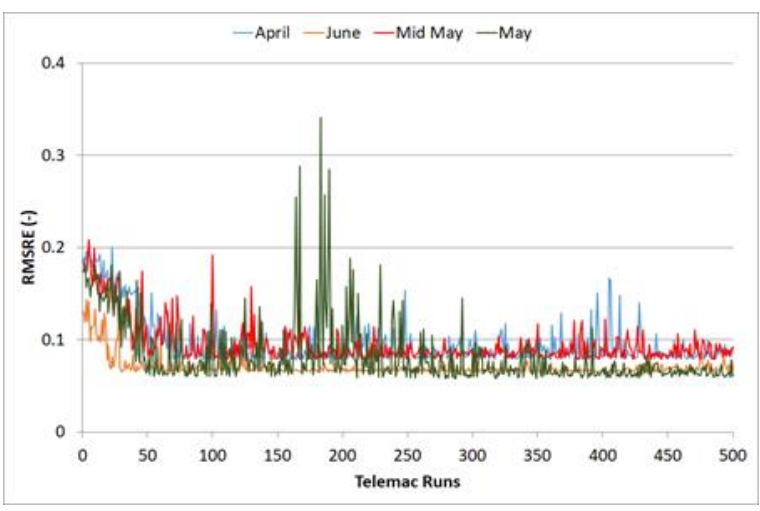

$5 b$

610 Figure 5 Convergence of the algorithm. 5a mean RMSRE for the 8 stations. 5b RSMRE at Pauillac

611

612

613

614

615

616

617

618 


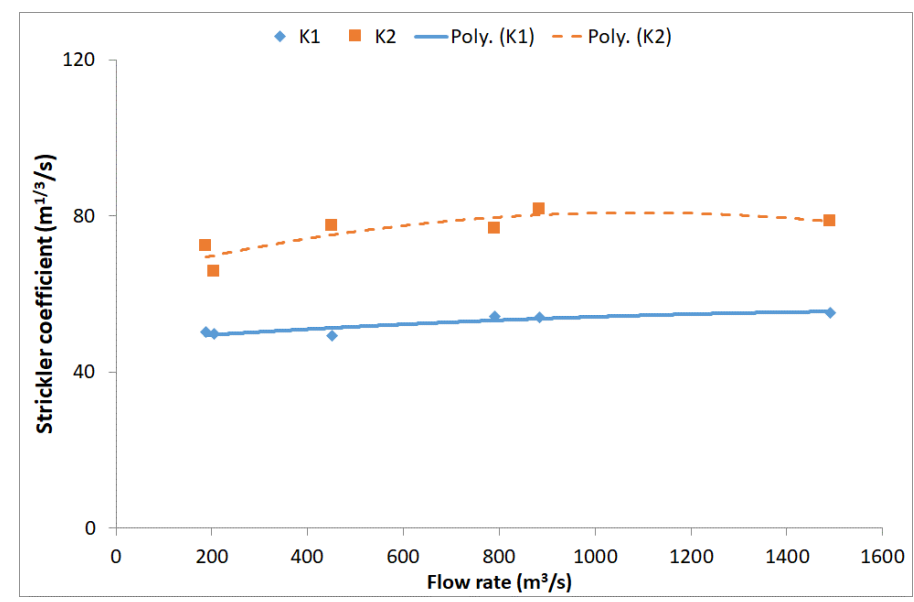

$6 a$

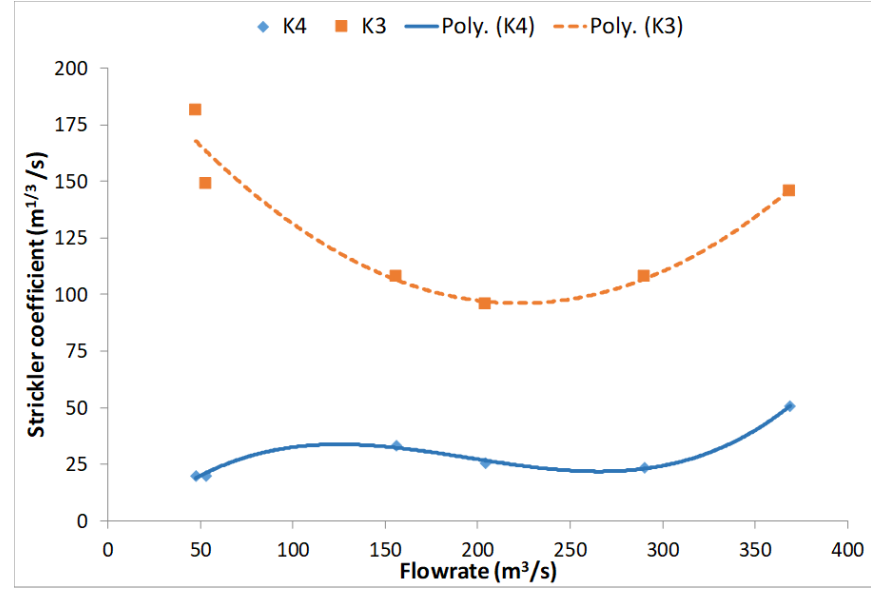

$6 b$

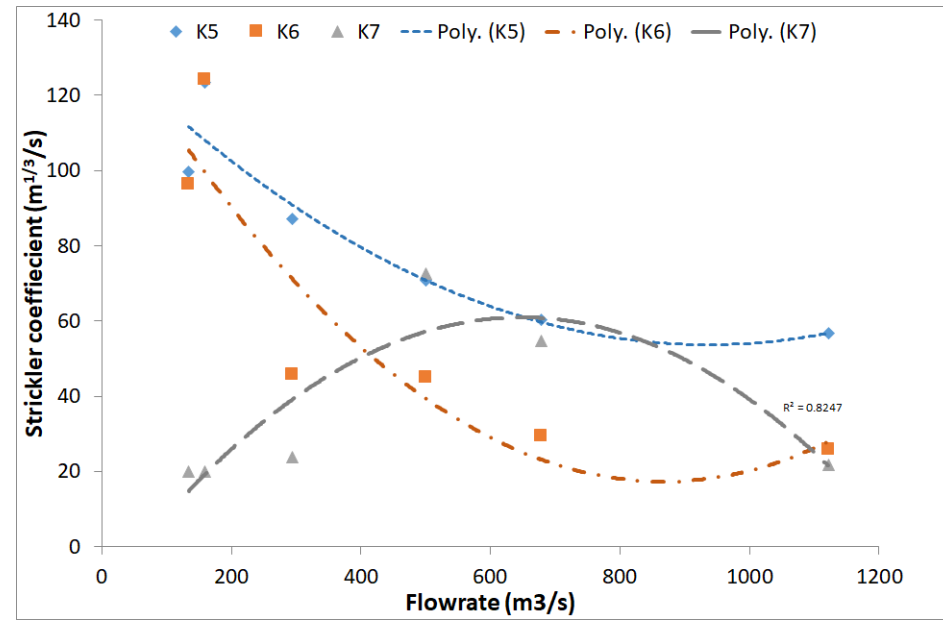

$6 c$

620 Figure 6 Evolution of the values for friction coefficient according to the total flowrate (Garonne and Dordogne). $6 a$ in the 621 central part with 7 zones distribution. $6 \mathrm{~b}$ Distribution in the Garonne with 7 zones distribution. 6c in the Garonne for the 6227 zones distribution 


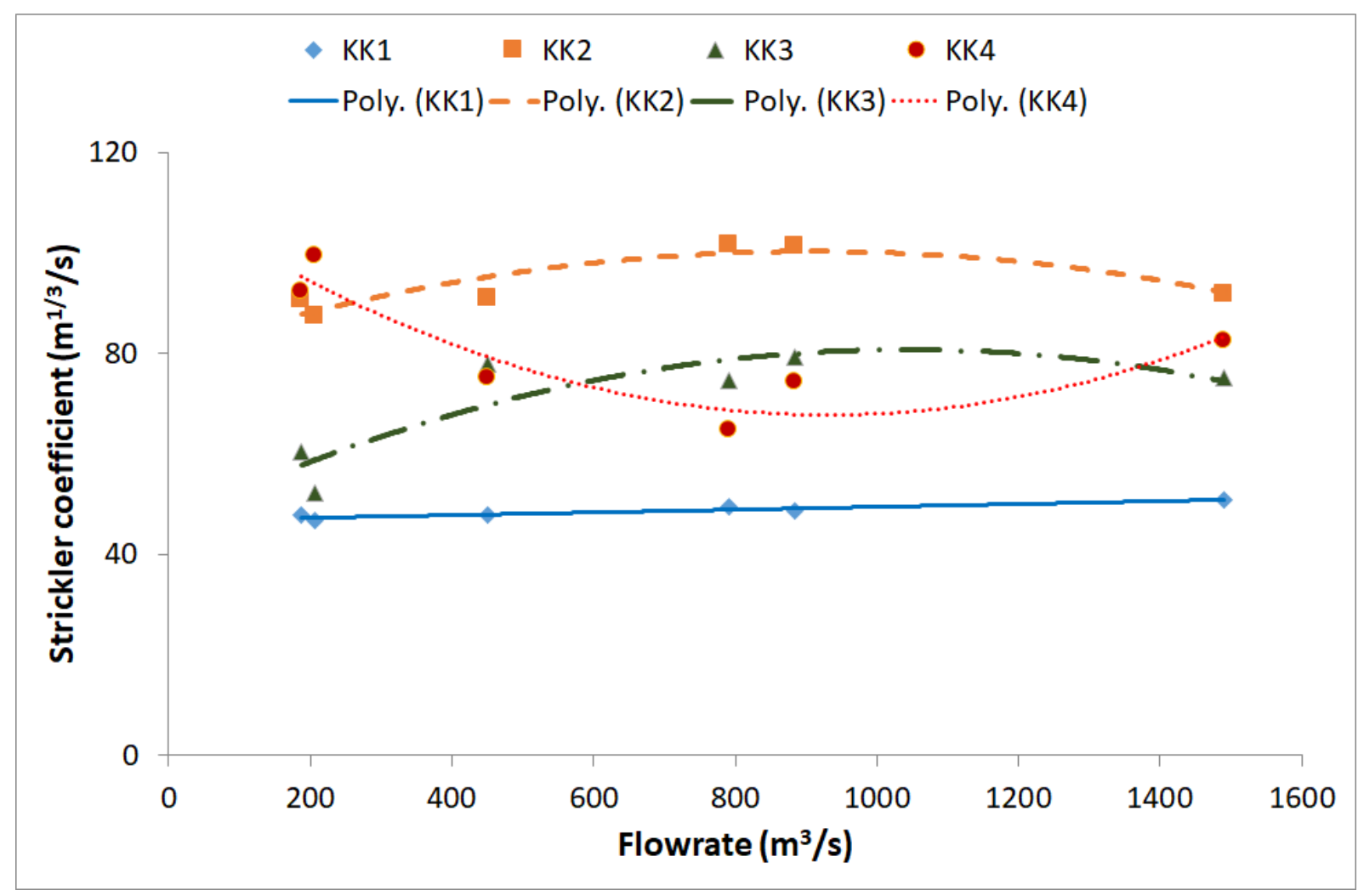

628 Figure 7 Evolution of the values for friction coefficient according to the flowrate in the central part with the 9 zones 629 distribution, Strikler coefficients are noted as KK to distinguish them from the 7 zones distribution.

630

631

632

633

634 


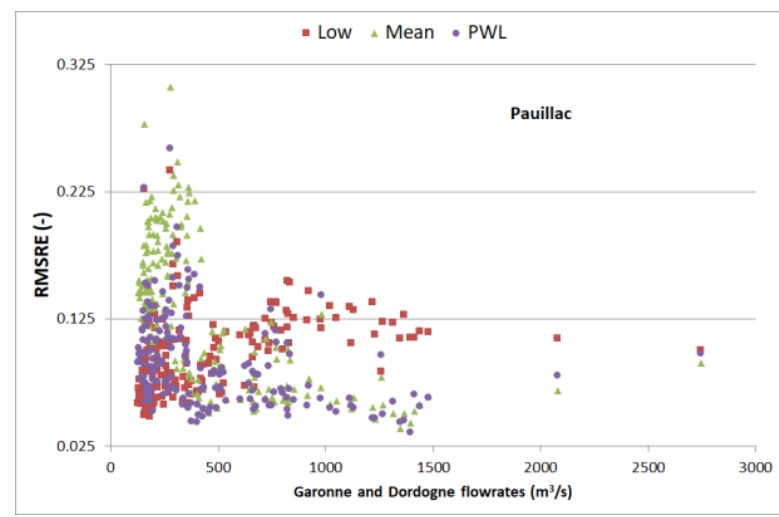

$8 a$

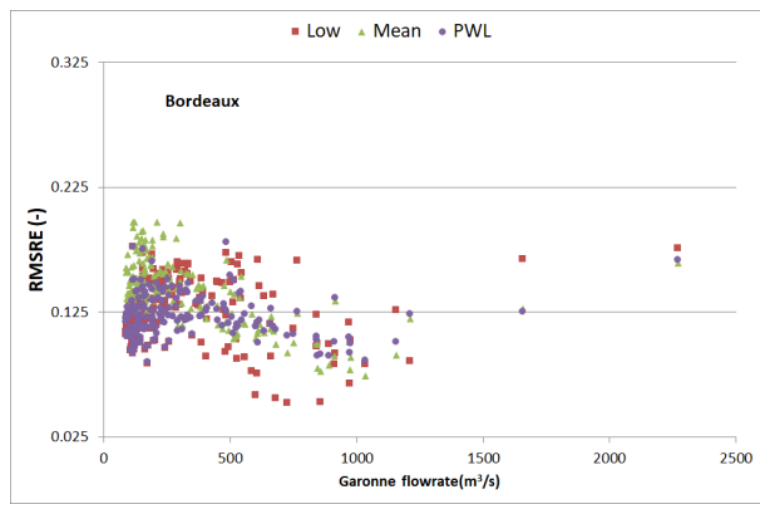

$8 b$

636 Figure 8. Evolution of the daily RMSRE with the flowrate at Pauillac (8a) and Bordeaux (8b). Daily tidal range

637 are using to estimate the relative accuracy. Flowrate is the sum of Garonne and Dordogne contribution at 


\begin{tabular}{|r|r|r|r|r|}
\hline $\begin{array}{r}\text { Total } \\
\text { flowrate } \\
(\mathrm{m} 3 / \mathrm{s})\end{array}$ & \multicolumn{2}{|c|}{ RMSREm - 7 zones } & \multicolumn{2}{|c|}{ RMSREm - 9 zones } \\
\hline & $\begin{array}{r}\text { Before } \\
\text { optimization }\end{array}$ & $\begin{array}{r}\text { After } \\
\text { Optimization }\end{array}$ & $\begin{array}{r}\text { Before } \\
\text { optimization }\end{array}$ & $\begin{array}{r}\text { After } \\
\text { optimization }\end{array}$ \\
\hline 187 & 0.149 & 0.119 & 0.152 & 0.121 \\
\hline 205 & 0.142 & 0.123 & 0.142 & 0.122 \\
\hline 450 & 0.157 & 0.117 & 0.153 & 0.116 \\
\hline 790 & 0.176 & 0.122 & 0.167 & 0.118 \\
\hline 883 & 0.183 & 0.107 & 0.173 & 0.111 \\
\hline 1490 & 0.173 & 0.091 & 0.163 & 0.089 \\
\hline
\end{tabular}

650

651

652

653

Table 2 Reached RMSE for two different mesh sizes

\begin{tabular}{|c|c|c|c|c|c|c|c|}
\hline Mesh & $\begin{array}{l}\text { Mean } \\
\text { RMSE }\end{array}$ & Verdon & Laména & Pauillac & Medoc & Ambes & Bordeaux \\
\hline $\begin{array}{r}\text { M1 - } 28000 \\
\text { nodes }\end{array}$ & 0.098 & 0.089 & 0.094 & 0.077 & 0.106 & 0.092 & 0.13 \\
\hline $\begin{array}{r}\text { M2 - } 76000 \\
\text { nodes }\end{array}$ & 0.087 & 0.090 & 0.070 & 0.069 & 0.100 & 0.085 & 0.11 \\
\hline
\end{tabular}

654 